\title{
The Global Citizenship MBA Orientation Program: Action Learning at the University of Michigan Business School
}

\section{Graham I. Mercer}

\begin{abstract}
The University of Michigan Business School's Global Citizenship Program is a two day action learning model conducted during orientation week. During these two days, teams of students, faculty and staff, along with corporate managers, work side-by-side on community projects. These projects are intended to help students understand the difficult issues and frustrations faced by community organizations. The students have opportunities throughout the year to continue to volunteer their business skills and time.
\end{abstract}

Implementing a successful Global Citizenship program requires courage, leadership and operational skills. It's not easy. It takes a champion; a leader who recognizes the need for revitalization and is willing to challenge the old way of thinking and transform it into new ideas, approaches and values. It also takes operational skill as a large complex program like this can quickly fall apart through inadequate conceptualization or poor planning.

The theoretical framework for the University of Michigan Business School's Global Citizenship was developed by Professor Noel Tichy, director of the business school's Global Leadership program. As part of the Global Leadership

Graham Mercer is director of the Michigan Business School's Global Citizenship program, an action learning program designed to develop graduate students with an awareness and appreciation of the inter-relationship between business-and-society. Prior to joining the Business School, Graham had considerable experience in action learning programming both as a corporate consultant and director of Outward Bound. program, senior executives are immersed in the problems of developing nations to assess business opportunities and investigate the role of business in dealing with the world's environmental and human capital problems. Through the knowledge gained from these immersion experiences, the concept of the MBA Global Citizenship program was formed.

In addition to providing the theoretical framework for Global Citizenship, Professor Tichy was the business school's change agent: the champion who challenged the status quo and invoked a new way of thinking. This was not a quick process. It required creating a ground swell of support and finding external funding of over $\$ 200,000$ to support the pilot program and first year's expenses.

Any transformational drama is not complete until change is actualized. This final act of transformation requires operational skill, diplomacy, and careful planning. In 1990, after having developed citizenship experiences for the Global Leadership program, I was asked by the Business School to develop and implement the MBA Global Citizenship program.

\section{Why the business school introduced global citizenship}

At the University of Michigan Business School there is a determination to become the world's best business school. The means of achieving that goal is innovation that is geared towards benefiting the students and the organizations that employ them. Business is changing at an 
unprecedented rate: moving rapidly to global markets, to network organizations, to a culturally diverse workforce, and to operations revolutionized by information and communications technology. In the face of these changes, the business school believes that innovation in management education and development is imperative.

The innovations being undertaken by the business school are designed to develop leadership, creative problem-solving and teamwork. However, in addition to developing these skills the business school is striving to develop leaders with an understanding of the broader responsibilities of leadership. It seeks to create leaders of conscience; individuals who have the vision to understand the long-term interrelationship between the well-being of corporations and the quality of life of the community. In the future, as these leaders advance to positions of corporate influence, they will be in a position to enlarge their corporations' definition of appropriate involvement to address environmental and human capital challenges.

The Global Citizenship program reinforces the business school's viewpoint that management is a performing art, that leadership is hard, sweaty work, that you have to roll up your sleeves, pitch in, and work effectively in teams to get things done, and that business and the communities where they operate are intertwined in many ways. An important side benefit is that the students, in just a few days, go from a group of strangers to a high energy, cohesive team ready to work and learn together.

\section{Underlying theoretical guidelines}

As we approach the end of the 20th century, nations the world over are struggling with a web of issues relating to population, the natural environment, social justice, and poverty. These issues affect the well being of nations and the quality of life of the world's population. The complexity of these issues demand more than government intervention can accomplish or should attempt and are forcing business to rethink their role as global citizens.
Global Citizenship is not the old style of "good citizenship". It's not simply doing good deeds or offsetting the damage a corporation might do to the local ecology with compensating measures, nor does it simply mean inculcating employees with a sense of civic obligations to their local communities. While these are important aspects of corporate responsibility they are not how we define Global Citizenship. Global Citizenship entails an understanding and awareness of future trends that will affect both the climate for doing business and the quality of life of the world's population.

As we move into the 21 st century global businesses will find themselves increasingly intertwined with global political, social and environmental issues that will force them to redefine their role as a potent force for world integration. This force coupled with the pressure being exerted by a burgeoning world population is determining the need for Global Citizenship.

World population growth is the single, most pervasive factor affecting the world today. Demographic projections by the World Bank estimate a doubling of today's population by the middle of next century with the highest growth rates occurring in the world's poorest countries. Accompanying this massive population growth is a rapid increase in urbanization. U.N. projections suggest that 60 percent of the world's population will be urbanized by early next century, compared to only 25 percent in 1950. When you factor in the population growth since 1950 this translates to very large numbers indeed.

It is a mistake to associate population pressures only with specific countries like India or China. Since resources are scarce, population has a dramatic impact on every other social and environmental issue; and its effects ignore geopolitical boundaries. A rapidly growing population can strain a country's ability to produce enough food and provide sufficient housing, education and health care. Often overlooked, the size of the human population is the most pressing environmental problem. People drain the earth's nonrenewable resources, release toxic chemicals into the environment, consume fossil fuels which add greenhouse gases to the atmosphere, and cause the extinction of other species. Overpopulation 
directly determines or greatly contributes to virtually every environmental and social problem facing the nations of the world today.

\section{The global citizenship approach}

As shown in Figure 1 Global Citizenship starts with an understanding of cultural differences and social and environmental issues. This is a critical first step, without which the basis for establishing values or making long term commitments does not exist.

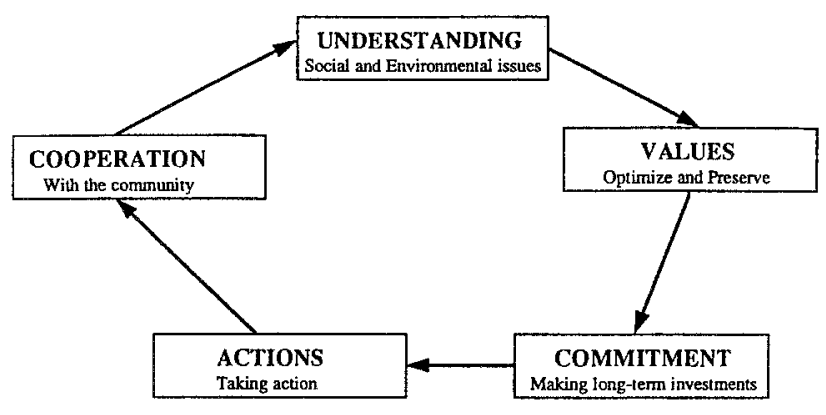

Fig. 1.

Values must be based on the issues and how they effect the well-being of the community and the people and organizations that live and operate within them. Without a firmly held and articulated set of values there can be no meaningful long-term commitment. Action is an outgrowth of commitment and when driven by deeply entrenched values results will eventually be achieved. Given the complexity of the issues that need to addressed all action must be a cooperative effort between concerned organizations and the surrounding community.

\section{Defining the problems}

Human capital and environmental problems respect no boundaries. They challenge the world with equal persistence. While the broad global issues can be categorized into main headings, their magnitude and specific local needs can vary dramatically from country to country. The successful global company orients its citizenship approach to meet the requirements of the local conditions. The Global Citizenship program considers population growth to be the primary driver of the world's human capital and environmental problems.

As shown in Figure 2, the following five major human capital issues are examined:

(1) Distribution of wealth - Differences between the rich and the poor play an important role in the social, as well as economic, development of a country.

(2) Nutrition - Getting enough to eat is a daily challenge for millions of people around the world.

(3) Health - Different levels of development, different climates, and different social practices produce very different health care problems.

(4) Housing - Local standards vary greatly, but most countries do not have enough housing to meet the needs of their population.

(5) Education - The education level of a population plays an important role in determining its ability to develop and respond to problems.

As shown in Figure 2, the following four major environmental issues are also examined:

(1) Toxic Pollution - Industrial pollution of air and water is a serious problem in many areas. Often the effects of pollution may be found far from its source. Examples of this include agricultural and industrial pollution of waterways and oceans; and

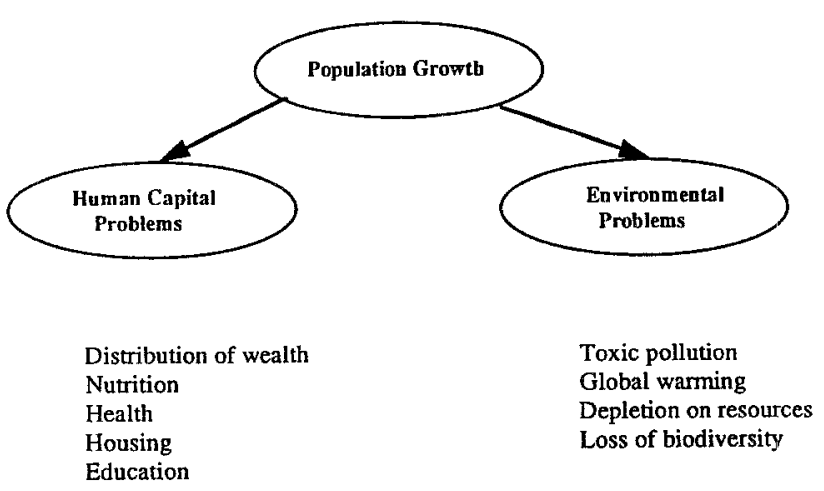

Fig. 2. 
the burning of sulfur containing fuels which can produce acid rain.

(2) Global Warming and Climate Change The burning of carbon based fuels and the creation of petrochemicals is rapidly changing the composition of the earth's atmosphere. This change is causing a gradual warming of the planet and an increase in the amount of ultra-violet radiation reaching the earth's surface. This situation may result in dramatic changes in the climate and a rising of the sea-level.

(3) Depletion of Non-Renewable Resources - Virtually all industrial societies depend on the exploitation of finite natural resources. Not just commodities like oil and minerals but important physical features like topsoil, potable groundwater, and old growth forest exist in limited supply. These resources are being consumed at rates in which they will be exhausted within decades or centuries.

(4) Loss of Biodiversity - Many of the planet's plants, animals and microorganisms are presently threatened with extinction. Most are disappearing without ever having been identified. There are practical, aesthetic and ethical reasons for concern about human-caused extinction.

Issues of human capital and the environment are interconnected with economic development; neither can be accomplished without the development of a successful economy. Successful economies are a complex mix of factors that determine the socio-economic future of an area and of the people and enterprises within it.

For a nation to be a successful, long-term competitor in the global marketplace its economy must develop without depleting social, human, or environmental resources to stressed levels. Economic growth creates dynamic forces that yield problems, challenges and opportunities for nations and people everywhere. Any citizenship strategy will have limited success without the backing of a healthy and sustainable economy.

\section{The global citizenship program}

Global Citizenship is a year long program that starts with pre-reading material and finishes with a final workshop (see Figure 3). In total there are about six hundred and eighty participants consisting of four hundred and twenty entering full-time students, seventy international exchange students, sixty faculty, sixty corporate managers and seventy team leaders (second year MBAs). It is a values driven program that is expected to provoke critical thinking on the troubling social and environmental issues that surround us, to explore how these issues affect corporate wellbeing and our overall quality of life, to develop within our students a commitment to pursuing long-term solutions, and to develop future leaders with a broad leadership perspective. As part of the program students are introduced to organizations and community leaders who are unbelievably entrepreneurial, accountable, compassionate and action oriented. From these leaders they learn what it takes to be successful in trying circumstances and hopefully, they become inspired by their accomplishments.

Pre-reading material. Prior to the start of the program all participants receive a substantial pre-reading package. This is mailed to each student four weeks prior to the Orientation Event and it presents the intellectual argument for Global Citizenship. This argument is used to "frame" the two-day, action learning experience. The pre-reading material is in the form of a briefing book which consists of an intellectual framework, a collection of best citizenship practices by major corporations, and a series of articles on education, economic development and the environment.

Orientation event. This is a two-day program that starts during orientation when teams of entering students are partnered with corporate managers, faculty, and community agencies and immersed in an intense, community experience. These two-days however, are more than just an experience, they are a reflection on that experience and a rendering of it into words so that it can be subjected to disciplined thinking. Throughout 


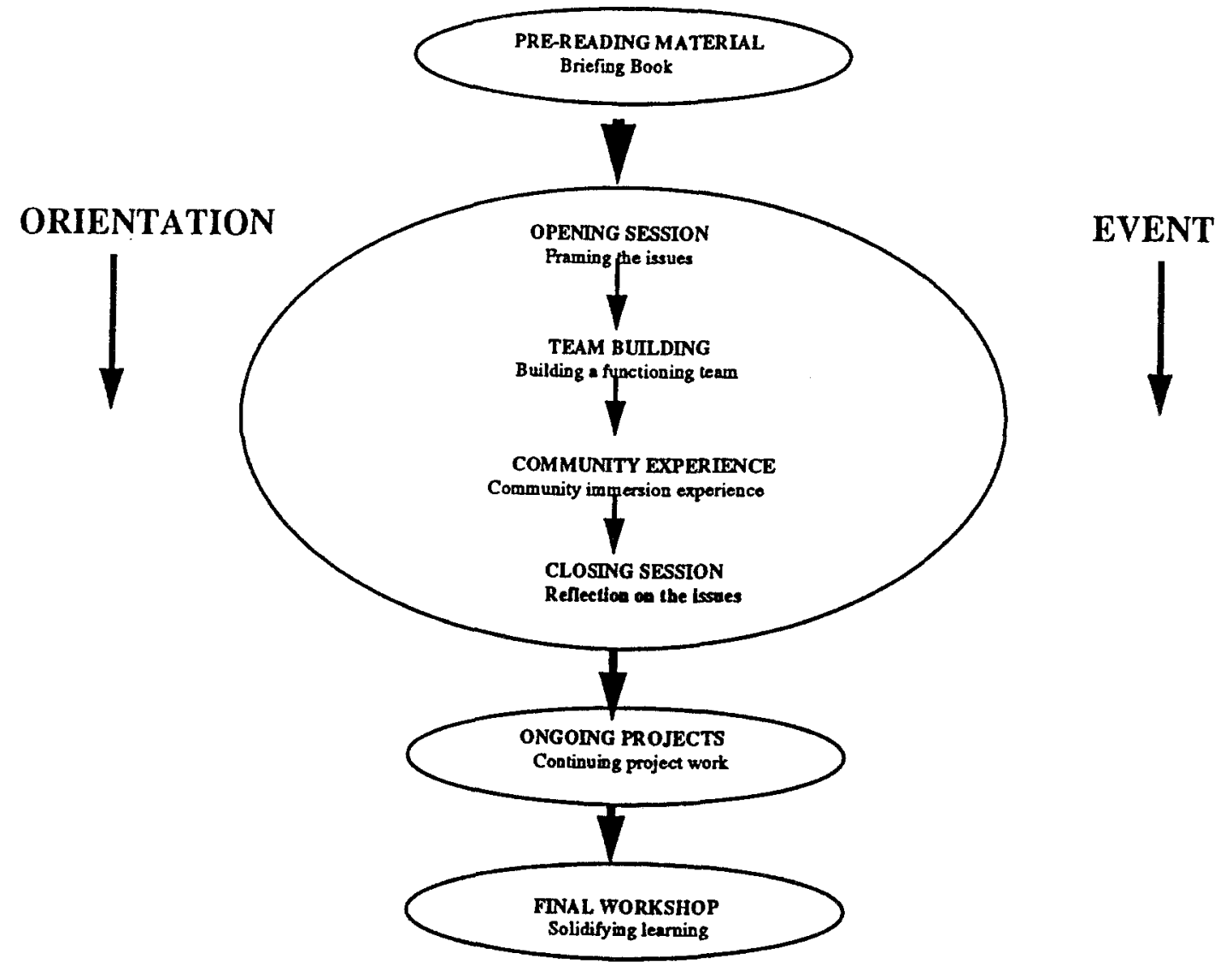

Fig. 3.

the experience each team is partnered with a student facilitator who helps the team understand the issues through a process of individual and combined reflective thought.

For ease of explanation the Orientation Event can be subdivided it into an Opening Session, Team Building, Community Experience and Closing Session. In practice these subdivisions are seamless with each one building on its predecessor.

Opening session. This is the formal part of the orientation event. In this session critical citizenship observations are provided by the Dean and a CEO of a major, transnational corporation. This formal session sets expectations, creates excitement and provides a global overview of citizenship issues. This is a two hour, formal assembly with the speakers on stage in a large auditorium.
Team building. As the two-days are a team experience, the program begins with building some basic team skills. This is accomplished through a series of outdoor, problem solving exercises (see Appendix 1). These exercises are designed to develop skills directly relevant to team performance and leadership. In these introductory exercises new approaches are encouraged and the results discussed and examined in a non-evaluative manner. To assist in the learning, a framework for diagnosing and improving team effectiveness is provided. Throughout the program a second year MBA student is assigned to each team to assist them with their processing. This student facilitator will have participated in the program the year before and have undergone facilitator training.

Community experience. The bulk of the two days is spent with local non-profit agencies working on community projects. As the total number of 
participants in the Global Citizenship program is close to seven hundred, immersion in a single project is almost impossible. To alleviate this problem the participants are subdivided into six sections and each are engaged in different projects. Each of these six sections has a major corporate partner who provides executive participants and guest speakers. In total Global Citizenship partners with eighteen non-profit organizations and conducts its activity in four different metropolitan regions (see Figure 4). Each project is designed to expose a range of issues on education, social and economic wellbeing and the environment.

Prior to immersion in the community each section is given detailed, background information on the agencies they will visit and the community issues and problems they face. As they work with these agencies the students are asked to assess the scope of the problems the agencies address and their effectiveness in meeting the needs (see Figure 5). At the end of the two day experience each section, through an established team process, is asked to form a plan for continuing action.

Closing session. The two-day experience finishes in the same auditorium as the Opening Session. Here each student section reports its learnings back to the entire assembly and states its commitments to future action. A guest speaker responds to the students and delivers a final address.

Ongoing projects. Throughout the academic year student volunteers continue to work in the community on a wide variety of projects. These projects range from developing business and marketing plans for community agencies to a mentoring program for the local school system. These projects are conducted by the first year students and the participation rate is approximately twenty five percent. All projects are conducted on a non-credit basis.

Final workshop. The program ends the following

\section{Community Partners}

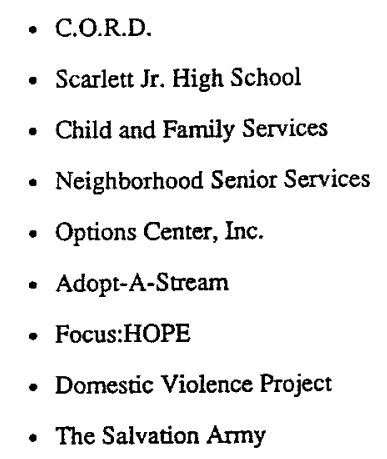

\footnotetext{
- River Partners Program

- Joy of Jesus/Ravendale

- Church of Messiah

- People in Faith United

- Core City Neighborhood

- Project GREEN

- Prospect Place

- Detroit Rescue Mission

- Harbor Lights
}

Corporate Partners \& Participants

- Ameritech
- AT\&T
- Detroit Edison
- Exxon Corporation
- Ford Motor Company
- General Motors
- Merck \& Co., Inc.
- Upjohn Company

- Arthur Anderson

- Bull Worldwide

- Dow Chemical Company

- First of America Bank

- General Electric Company

- IBM

- NBD Bank

- Whirlpool Corporation

Fig. 4. 


DAY 1
\begin{tabular}{|l|l|}
\hline Discussion Guidelines & $\begin{array}{l}\text { 1. Individual reflection time (10 minutes). } \\
\text { 2. Team time to share thoughts and reactions (30 minutes). } \\
\text { 3. Team presentations to section (30 minutes). }\end{array}$ \\
\hline Assignment Questions & $\begin{array}{l}\text { 1. Construct a profile... of the agency and its staff. } \\
\text { 2. Assesses the source of the problem(s)... } \\
\text { 3. Determine how the problem is being alleviated... } \\
\text { 4. Assess the effectiveness of the organization.... }\end{array}$ \\
\hline
\end{tabular}

\begin{tabular}{|c|c|}
\hline Discussion Guidelines & $\begin{array}{l}\text { 1. Individual reflection time (10 minutes). } \\
\text { 2. Team time to share thoughts and reactions ( } 45 \text { minutes). } \\
\text { - The problem and its relationship to corporations. } \\
\text { - Your team's future citizenship efforts. } \\
\text { 3. Section time to share and discuss program learnings ( } 45 \\
\text { minutes). } \\
\text { Discussion is conducted in a fish bowl with a } \\
\text { representative from each section forming a core team to } \\
\text { share learnings and develop a section viewpoint. } \\
\text { 4. Two representatives selected from the core team. } \\
\text { Present the section's viewpoint at the closing session. }\end{array}$ \\
\hline Assignment Questions & $\begin{array}{l}\text { 1. Which area was impacted (education, environment or } \\
\text { economic development)... } \\
\text { 2. What relationship do corporations have to the problem... } \\
\text { Did they create the problem or are they impacted. } \\
\text { 3. What relationship do you have to Global Citizenship... } \\
\text { What personal relationship do you have to Global Citizenship } \\
\text { and future citizenship efforts? }\end{array}$ \\
\hline
\end{tabular}

Fig. 5.

March with a half-day workshop that focuses on citizenship issues. This workshop is limited to next year's team leaders along with a selection of faculty, non-profit and corporate managers. The workshop is designed to promote understanding on critical environmental and social conditions through an examination of the problems and issues facing our inner cities. This examination is conducted from both a corporate and community perspective. This is a mandatory workshop for future team leaders.

\section{Specific outcomes of the global citizenship program}

As part of the Global Citizenship program student volunteers continue to work with the organizations they visited during orientation. Volunteer efforts range from providing a simple service to undertaking major business and planning projects. One of the most significant efforts that has been undertaken is the development of a mentoring program with the local school system. This highly successful program involves a partnership between University of
Michigan MBAs, General Electric, and a local school. The program, which was started in 1991, was designed to be a demonstration model suitable for distribution to other communities. Since its inception it has been an outstanding success and this year the General Electric Foundation granted the partnership $\$ 25,000$ to evaluate and document the program so that it can be replicated in other communities.

Another section developed a comprehensive business plan for an expanding, community organization in Benton Harbor which is 200 miles from the Michigan Business School campus. This was a considerable undertaking given the students busy schedules and the travel time the project required. Yet another section developed a marketing and fund raising proposal for a community group including developing brochures and a promotional video. Numerous task orientated projects like clean-ups and fund raising events have been organized. One section helped promote a new company that was being set-up as a profit venture to aid the homeless. This year an independent study in corporate strategy will be offered to teams developing business plans for non-profit organizations. 
A close connection has also been formed between the Business School's environmental management program and Global Citizenship. This has proven to be very beneficial as Global Citizenship creates for the students a graphic connection between business and the environment. Ongoing independent studies are expected to be the outgrowth of this close alliance.

Many of the groups the students work with are religious organizations. This has never been an issue as we are concerned with the problem being addressed rather than the religious affiliation of the organization. The program considers any project to be appropriate if it addresses a fundamental problem faced by the community.

An outcome that is more intangible but very important is the ability of the program to develop a camaraderie and sense of team out of a group of strangers. It bonds the entering students and provides them with a high energy start to their MBA experience.

\section{Developing an effective global citizenship program}

A well-organized and -executed Global Citizenship program is an enlightening, educational experience but the inverse is equally true as poor logistics and operations can discredit the best conceptual and educational plans. The effort required to mount a program of this magnitude should not be underestimated. It takes time, money and commitment from an experienced program manager who has a strong understanding of corporations and the community. The importance of an intellectual framework cannot be over emphasized as it shapes the program and establishes the learning. As sh own in Figure 6 there are six key factors:

(1) Catalyst for Change - To institutionalize a program like this you need a champion; a person who is willing to change the way things have been done in the past. It requires developing top level administrative support and a positive faculty attitude. Not everyone will be initially enthusiastic. Negative attitudes can only be transformed when you prove that you understand the issues, can articulate why the business school should be involved, and demonstrate your administrative capability to organize such a complex event.

(2) Frame the Issues - To embed a citizenship program within a major Business School it must have a strong intellectual framework. Without this intellectual framing student and faculty cynicism may occur. You cannot assume that students or

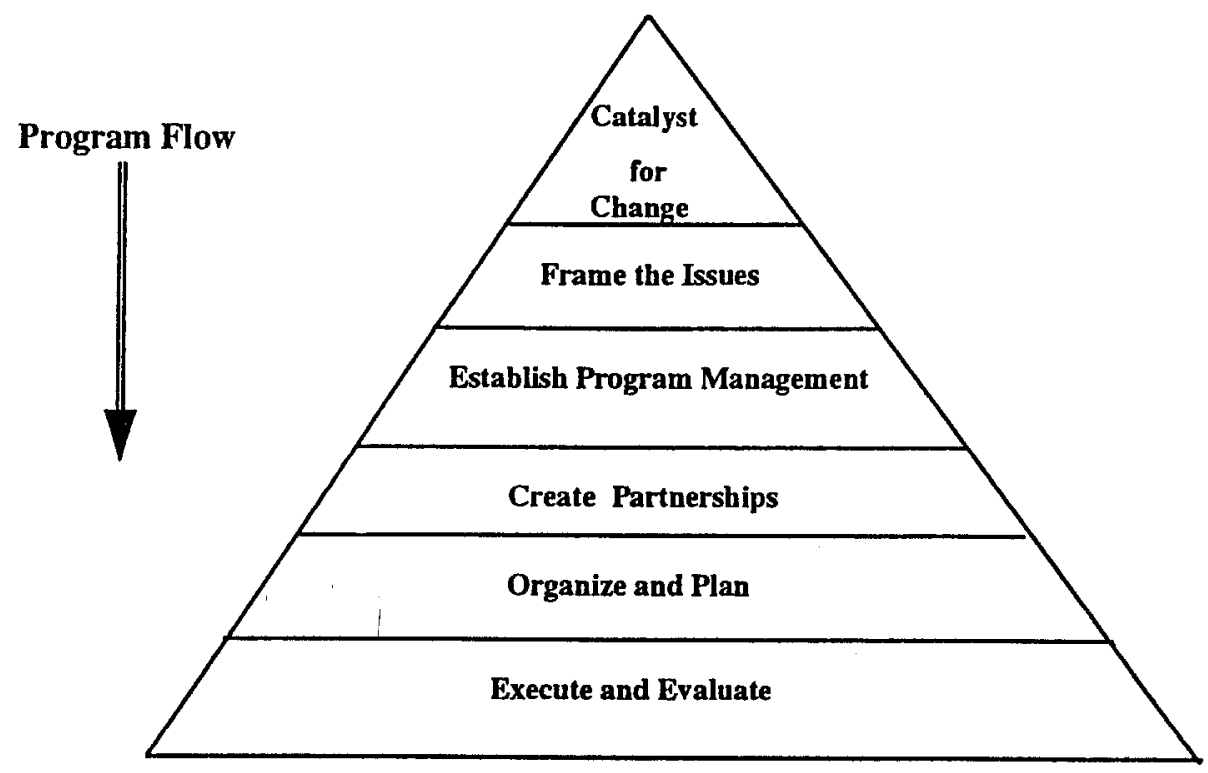

Fig. 6. 
faculty understand citizenship issues or that they can put them into a larger societal or business context. In the Global Citizenship program we spend considerable time framing the issues through pre-reading material, workbooks and by corporate and community presentations.

(3) Establish Program Management - An experienced program manager, who is knowledgeable about action learning programming is required. This is more than just an administrative position. The person must be capable of creating learning experiences, training team facilitators and articulating citizenship issues to a wide range of participants.

(4) Create Partnerships - For a program like this to be effective it must involve all the stakeholders. It must have heart and soul and the issues and problems must be seen and discussed in the environment in which they arise. This type of program cannot be created in isolation. It takes the commitment of the community and corporate participation to make it happen in a meaningful way.

(5) Organize and Plan - Organization is everything. An action learning program of this magnitude can quickly fall apart through poor planning; bus drivers must know where they are going, lunches must arrive on time, work tasks need to be organized and equipment made available. Poor logistics can quickly cause a welldesigned program to fail and create resentment amongst the students, community and corporate partners.

(6) Execute and Evaluate - Once the program has started it is too late to worry about organization and planning. As groups are well spread out effective execution can only occur if group leaders have the knowledge and are empowered to make on-the-spot decisions. To be able to do this the group leaders need to be well trained, they need to know the community issues, and they need to be familiar with the educational objectives.
In the Global Citizenship program we evaluate the program twice through extensive student evaluations. This happens immediately after completion of the orientation event and then again several months later. This dual evaluation gives us an effective measurement of the lasting impact of the program.

The University of Michigan Business School is committed to developing in its students an understanding that with privilege and power come responsibilities. As a school we have made significant progress in creating this understanding. Given the urgency and complexity of the social and environmental problems that surround us this effort must continue as a priority for this decade and many decades to come.

\section{Appendix}

\section{Team process}

This model provides a framework for diagnosing and improving team effectiveness. The model is hierarchical and starts with goals, then allocates work/roles, then identifies team process, and finally deals with personalities, styles and cultural differences. Process loss can be minimized by systematically working down through each layer.

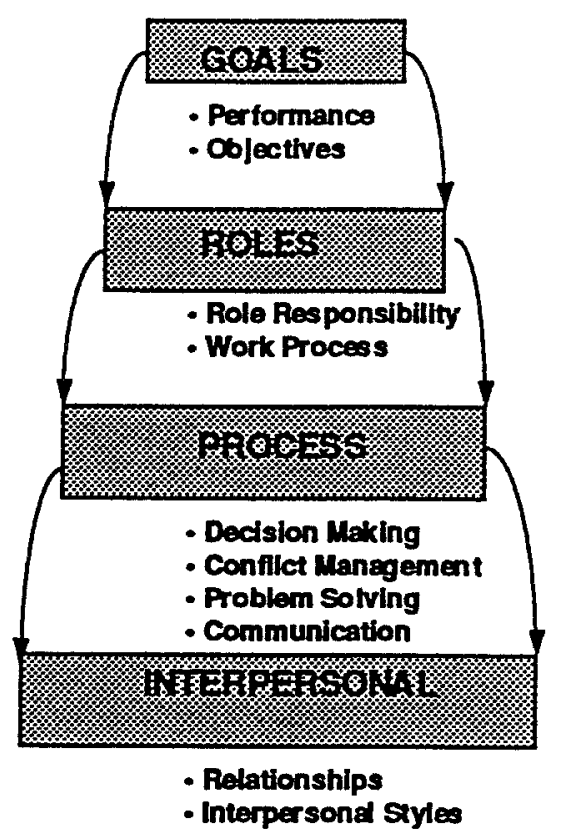


Goals: Goals are clear and people are committed to them. $\begin{array}{lllll}1 & 2 & 3 & 4 & 5\end{array}$

Roles: The work is organized in a way that works towards accomplishing goals.

$\begin{array}{lllll}1 & 2 & 3 & 4 & 5\end{array}$

Team Process: Decisions are based on expertise and information.

Interpersonal Styles: There is trust and openness in communication and relationships.

$\begin{array}{lllll}1 & 2 & 3 & 4 & 5\end{array}$

RATE YOUR TEAM

$1=$ To a little extent $5=$ To a great extent.

Goals. The critical ingredient of all high performing teams is goal clarity. These teams all have a clear understanding of the goal to be achieved and are committed to that goal. Ineffective teams frequently have a goal that has lost its focus or become politicized. When clarity exists there is a specific performance objective that can be used to determine, unequivocally that the team's objective has been met.

Roles. A critical factor in the development of a high performing team is the structure of the team itself. Structure is the relationships, roles and responsibilities that exist . . the framework that allows team members to mesh as they pursue interdependent tasks. This framework should be clearly understood by everyone and communicated frequently.

Team process. Team process can be defined as how the team makes decisions, resolves conflict, and shares information. Teams that are truly effective do not always agree but they but they do handle conflict in a way that transfers differences into a positive force. This force creates an open and free exchange of ideas, information and feelings. Critical to team process is effective decision making. An effective team knows how each decision will be made, such as when consensus is required, when a few people can make the decision, or when a poll is acceptable.

Interpersonal. Teams are in essence communities and how its members relate to each other and the community has a major impact on the team's spirit, emotional well-being and overall effective. Team problems invariably manifest themselves in this area but in the majority of cases the problems originate in the structure or purpose of the team. Most often when the structural problems are resolved community and personal relations dramatically improve.

University of Michigan, Global Citizenship Business School, Ann Arbor, MI 48109-1234, U.S.A. 